\section{A fúria escancarada da memória}

GISELA DÓRIA

In this text I intend to address the issue of memory as the central axis of this work of Rodrigues, articulating it with forgetfulness and negations of history. Such articulation leads to the notions of "memorylessness" and "discursive a-memory" (Robin/Paveau, 2013). Bluntly, Fúria speaks of the memory of a country that poorly cultivates, documents and reflects on its history, based on a dramaturgical construction that shows the tensions that emerge from such absence. Violence, loneliness, fear, oppression, prejudice, racism, beauty, seduction, complicity and trust, emerge on the scene in a non-linear historical path. Epic building and dismantling a parade, the work creates metaphorical images in a kind of hallucinating spiral. The show, entitled to its title, exposes the countless wounds of a society at risk. Here we can perceive all the characters in this story - past, present and potential future - so forgotten and neglected. Noble European settlers, slaves, mythological images, politicians, street dwellers, prostitutes, references to money, power and sex. Although Fúria makes a ruthless portrait of Brazil's current moment, it seems evident that it is not only talking about this South American society, but about a whole Western capitalist society in deep crisis and in urgent alertness.

DANÇA CONTEMPORÂNEA / MEMÓRIA / A-MEMÓRIA / NÃO-MEMÓRIA / DRAMATURGIA

Eu não estou indo embora,

Vou ficar aqui e resistir ao fogo. SOJOURNER TRUTH

A edição de 2019 do Festival Dias da Dança - DDD ${ }^{1}$, na cidade do Porto, Portugal, teve como foco o Brasil. Com uma curadoria que trouxe coreógrafos consagrados a par de jovens artistas em ascensão, o DDD procurou

Festival Dias de Dança - DDD é um evento anual internacional de dança contemporânea organizado pelo Teatro Municipal do Porto/Câmara Municipal do Porto, com a coorganização das Câmaras Municipais de Matosinhos e Gaia, no contexto da Frente Atlântica. Consultado em
www.festivalddd.com, 12 de outubro de 2019 . dar a «conhecer a produção artística contemporânea brasileira, num retrato do Brasil dos nossos dias».

Falar de «um retrato do Brasil de nossos dias» é adentrar em um tema bastante complexo. O atual governo brasileiro, eleito no fim de $2018 \mathrm{e}$ encabeçado pelo presidente Jair Bolsonaro, tem alcançado com frequência as manchetes da mídia internacional. No entanto, tal visibilidade não tem existido pelos melhores motivos; pelo contrário, ela está associada à relação deste governo com a milícia e com crimes ambientais e de corrupção-além de escandalosas declarações misóginas, machistas, homofóbicas e racistas. Nesse sentido, se olharmos para o atual (des)governo brasileiro, o que vemos não é uma boa imagem do país.

Felizmente, o DDD mostrou outras facetas deste panorama relacionadas com uma resiliente produção artística nacional, tendo possibilitado, por sua vez, um olhar alternativo sobre o Brasil dos nossos dias. Um Brasil que não é somente um retrato decadente divulgado pela mídia internacional.

Mas se, de fato, os escândalos atuais são chocantes, a barbárie e as injustiças históricas vividas neste país não são um fenômeno recente; pelo contrário, basta uma breve incursão histórica para nos lembrarmos de um país que sofreu a violência e a exploração da colonização, da escravidão, e que, como aponta Katz (2019), «ainda não enfrentou as consequências da ditadura que viveu, de 1964 a 1985». Entretanto, parece que o exercício de cultivar a sua própria memória é uma das grandes dificuldades do povo brasileiro. Existe um lugar-comum nas narrativas locais, e mesmo internacionais, que apresenta o Brasil como um país sem memória. Eckert aponta as constantes referências «aos temas do subdesenvolvimento, do atraso, da marginalidade e do capitalismo selvagem como forma de tratamento conceitual das questões do barbarismo e da deformidade que presidem o ato de fundação do corpo social no Brasil com base nos sincretismos culturais, nas misturas das raças» (Eckert, 2000:3).

Ainda que tal lugar-comum seja reducionista, são muitas as representações que constroem o Brasil como um país sem memória. Basta lembrar o descaso com museus e prédios históricos, que ardem e reduzem a cinzas séculos de memória. ${ }^{2} \mathrm{O}$ que se põe em questão a partir de

2 Nos últimos dez anos, o Brasil viu queimar, pelo menos, oito prédios com arquivos históricos, sendo o mais grave e recente o incêndio ocorrido em 2 de setembro de 2018 no Museu Nacional, no Rio de Janeiro. Consultado em https://www.bbc.com/portuguese/brasil-45348664, 20 de outubro de 2019. 
tal comportamento é a perpetuação de um sistema opressor, cuja desigualdade social contribui para o aumento de uma sociedade cruel e violenta. A história do Brasil continua a ser uma história de apagamentos e silenciamentos. O desaparecimento foi a lógica da ditadura, onde se tentou apagar e silenciar inúmeros ativistas e jornalistas - foram centenas de mortos e desaparecidos políticos entre 1964 e 1985.

A violência vivida no Brasil é uma realidade que não pode ser negada e que, ainda que muitas vezes banalizada e normalizada, tem sido retratada e denunciada pelos artistas nacionais. Tal denúncia se fez evidente nesta edição do DDD, onde contradiscursos emergiram em todas as obras e novas narrativas foram apresentadas pelos grupos brasileiros que, por sua vez, partiram de uma percepção vinda das margens, das periferias urbanas e de lugares cuja produção artística é ainda pouco ou nada fomentada. De entre os coreógrafos consagrados que estiveram presentes no Festival, destaco Lia Rodrigues, que trouxe um trabalho recente chamado Fúria (2019).

\section{SOBRE O PERCURSO DE LIA RODRIGUES}

Lia Rodrigues nasceu em São Paulo, em 1956. Com formação em Balé Clássico e História, foi uma das fundadoras do grupo independente de dança contemporânea Andança, nos anos 7o. Entre 1980 e 1982, trabalhou na Compagnie Maguy Marin, em França, onde participou na criação de May B. Ao retornar ao Brasil, instalou-se no Rio de Janeiro, onde fundou sua companhia, a Lia Rodrigues Cia. de Danças, em 1990.

Em 2003, a Companhia deu início a uma parceria com as Redes de Desenvolvimento da Maré, no Morro do Timbau, onde instalou a sua sede. A Redes da Maré (como é conhecida) é uma instituição de organização civil que tem como missão «promover a consolidação de uma ampla rede de parcerias para garantir o desenvolvimento sustentável no maior conjunto de favelas no Rio de Janeiro, a Maré, a partir da articulação de pessoas e instituições comunitárias, da sociedade civil, de universidades, de órgãos públicos e da iniciativa privada».4 Quando se fala Favela da Maré, é importante ter-se a noção de que estamos falando de uma região com mais de 140 mil habitantes, que habitam cerca de 40 mil

casas, e que vivem sob o domínio de todas as facções do tráfico de drogas do Rio de Janeiro.

A partir das novas configurações que emergiram dessa nova residência, Rodrigues se propôs repensar a relação entre a dança contemporânea e os projetos sociais, acentuando de forma significativa o potencial político das suas obras coreográficas. Em 2007, dando continuidade à parceria com a Redes da Maré, Lia Rodrigues e sua colaboradora, a dramaturga Silvia Sotter, iniciaram um novo projeto, dessa vez na comunidade da Nova Holanda. Tal projeto deu origem ao Centro de Artes da Maré - CAM, que acolhe a sede da Companhia de Danças, além de abrigar a Escola Livre de Dança da Maré - ELDM.

Atualmente, a ELDM atua em dois eixos: o Núcleo 1-aberto aos moradores da Maré de todas as idades, oferece oficinas contínuas de variadas práticas corporais; e o Núcleo 2 - projeto de formação técnica, artística e profissional dirigida aos jovens da Maré e de outras regiões, com aulas diárias, teóricas e práticas.

Sem um apoio consistente do governo e do município carioca, Lia afirma que não somente ela e sua companhia carecem de apoios públicos como, de um modo geral, a dança contemporânea existe de forma precária no estado do Rio de Janeiro (Rodrigues, 2020). A coreógrafa reconhece que a subsistência dos seus projetos se deve graças a investimentos de algumas instituições europeias, com as quais tem construído parcerias ao longo de sua carreira, como a Fondation d'Enterprise Hermès e o Chaillot-Théâtre National de La Danse, por exemplo. Tais apoios, dentre outros, têm sido responsáveis pela viabilização de espetáculos e a manutenção das atividades artísticas e sociais promovidas pela companhia.

Fúria é um espetáculo híbrido, que transita entre a dança, o teatro e a performance, e que faz nascer a sua estética da constante tensão entre as dimensões ética, histórica e política. Como é comum nas artes contemporâneas, a obra propõe múltiplas leituras. No entanto, há mensagens que não deixam margens para ambiguidades na sua dramaturgia. A obra é clara ao denunciar imensos abusos e horrores vividos pelo povo brasileiro desde os primórdios da sua colonização. Neste trabalho, a história do Brasil é contada por outras vozes, diferentes das vozes hegemónicas 


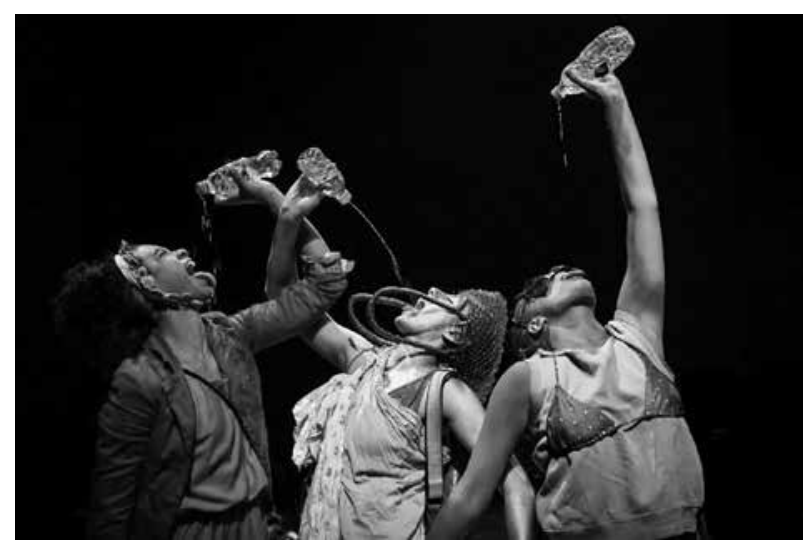

FÚRIA, ENC. LIA RODRIGUES,

LIA RODRIGUES CIA DE DANÇA, 2019 [F] SAMMY LANDWEER
FÚRIA, ENC. LIA RODRIGUES, LIA RODRIGUES CIA DE DANÇA, 2019, [F] SAMMY LANDWEER

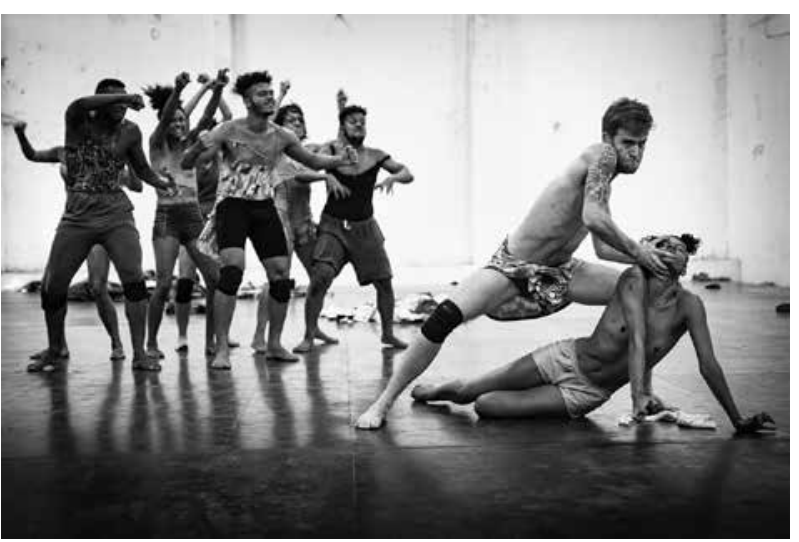

que escreveram e escrevem os livros estudados nas escolas. Não que exista um romantismo ou uma idealização na literatura pedagógica, uma vez que é possível perceber uma crítica ao sistema colonial e escravocrata em parte dos livros que recontam a história brasileira. Mas, de fato, esta história tem sido contada de um ponto de vista apenas: o dos «vencedores», os que tiveram a oportunidade de estudar e receber uma educação de qualidade - que no Brasil é ainda privilégio das classes dominantes, maioritariamente brancas, descendentes dos europeus.

Como aponta Ribeiro, «é importante lembrar que apesar da Constituição do Império de 1824 determinar que a educação era um direito de todos cidadãos, a escola estava vetada para pessoas negras escravizadas» (Ribeiro, 2019: 9). E não se pode negar que tal sistema ainda privilegia a população branca, ao passo que a negra segue inferiorizada, com dificuldades no acesso básico a direitos fundamentais que garantam uma formação pública de qualidade, serviços de saúde, segurança pública, moradia e distribuição de riquezas.

Há no Brasil o mito de uma democracia racial: a ilusão de que, em função da miscigenação e da ausência de leis segregadoras, não há conflitos entre negros e brancos no país. No entanto, o que existe, de fato, é uma profunda desigualdade social, que promove um sistema de violência e opressão na sociedade brasileira como um todo. Tal desigualdade é visível na produção artística nacional. Se a música popular brasileira é uma forma de cultura supostamente mais inclusiva e democrática, não se pode dizer o mesmo da dança cênica, do teatro e do cinema brasileiros. No campo das artes cênicas e audiovisuais, são poucas as experiências realizadas pela população negra; ou seja, a produção artística nacional é predominantemente produzida e fruída pela elite branca dominante.
No caso específico da dança, além da manutenção de tais estereótipos, há uma tendência evidente de reprodução de técnicas europeias importadas desde que a dança cênica foi introduzida no país, no início do século Xx. Embora nas últimas décadas tenha havido um esforço por uma democratização nas artes da cena, é possível afirmar que a companhia de Lia Rodrigues se destaca como uma das poucas companhias com grande visibilidade cujo elenco é formado por um grupo multicultural de bailarinos. Como aponta Sílvia Fernandes, desde a sua fundação nos anos 9o, é visível o interesse da coreógrafa em tocar nas feridas sociais e expor o contexto brasileiro em que se insere. A partir da mudança da companhia para a Favela da Maré, torna-se ainda mais evidente a opção da artista por uma arte que não evita abordar as tensões políticas, enfrentando abertamente as inúmeras crises sofridas pelo povo brasileiro, sem abrir concessões às demandas da cultura de mercado. Nas palavras de Fernandes:

No início da trajetória já é visível a opção pelo diálogo íntimo com as situações públicas, na projeção de um modo novo de configuração de político na arte, ligado à forma de fazê-la, organizá-la e produzi-la e aos dispositivos usados para provocar pensamento, pressupostos fundamentais de uma arte política. (Fernandes, 2018: 19)

Entretanto, não há espaço para romantismos na obra de Rodrigues, tão-pouco nenhuma disposição para reproduzir as tendências coreográficas da dança contemporânea europeia - ainda que Rodrigues não renegue a influência que tal dança teve na sua formação (Rodrigues, 2020). No que diz respeito às temáticas abordadas pela companhia carioca, a coreógrafa afirma que não faz um trabalho «sobre», mas um trabalho 


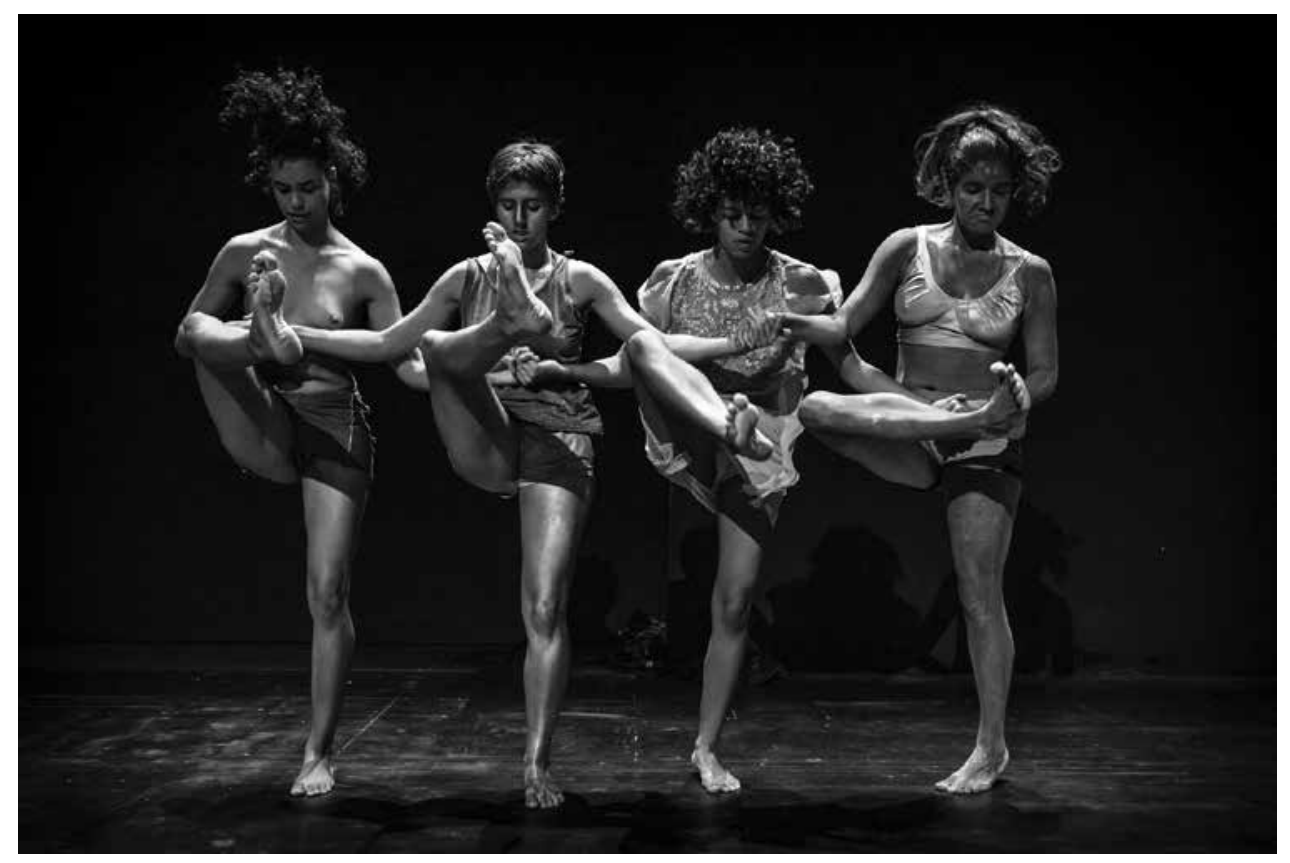

FúRIA, ENC. LIA ROdRIGUeS, LIA RODRIGUeS CIA DE DANÇA, 2019, [F] SAMMY LANDWEER

«com»; por outras palavras, ela não busca abordar um tema específico no seu trabalho, mas construir um assunto com o seu elenco, com as múltiplas referências encarnadas. No seu repertório-Encarnado (2005), Contra aqueles dificeis de agradar (2005), Pororoca (2009), Piracema (2011), Pindorama (2013) e Para Que o Céu Não Caia (2016) -, a artista realiza obras que tratam de forma poética muitas das angústias e preocupações da sociedade contemporânea brasileira.

Segundo a bailarina Carolina Repetto 5 , o processo de criação de Fúria se deu a partir de muitos incômodos e leituras partilhadas. Ana Maria Gonçalves, Octavia Butler, Mário de Andrade, Conceição Evaristo, Aimé Césaire, Clarice Lispector, Harriet Ann Jacobs, Achille Mbembe, Futhi Ntshingila, Carolina Maria de Jesus, Angie Thomas e Djamila Ribeiro são alguns dos autores mencionados como referências adotadas. Tais leituras promoviam debates e geravam estímulos para improvisações que foram construindo a dramaturgia do espetáculo. ${ }^{6}$

Rodrigues afirma que esta obra representa, antes de mais nada, um sentimento de perplexidade e indignação perante o que a sociedade

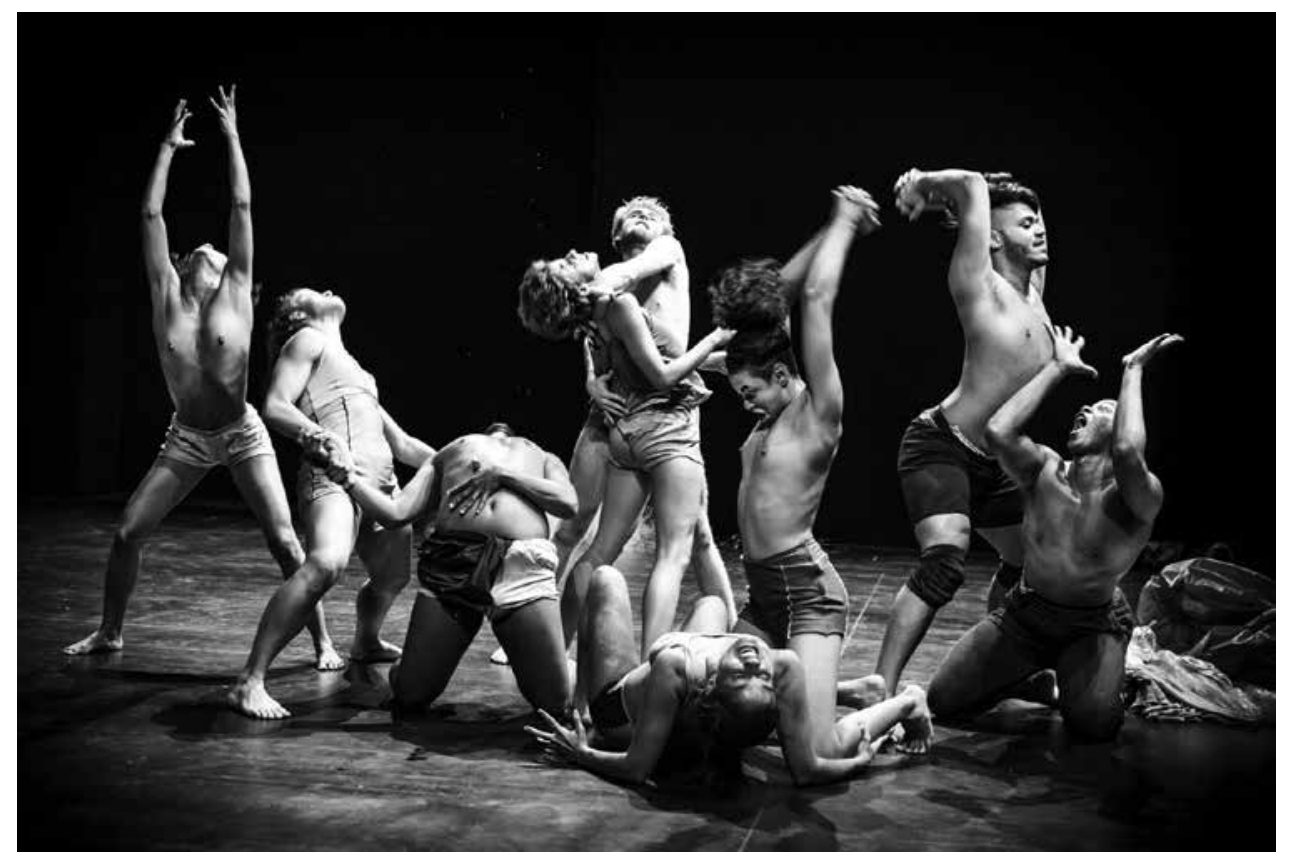

FÚRIA, ENC. LIA RODRIGUES, LIA RODRIGUES CIA DE DANÇA, 2019, [F] SAMMY LANDWEER

brasileira vive, mas também associa Fúria a uma «energia que te move, uma energia de estar sempre em ação». Quando questionada em relação à colaboração artística com o elenco, Rodrigues responde que não se sente em posição de «dar voz aos seus bailarinos». A coreógrafa, que se reconhece como uma mulher branca de classe média com todos os privilégios sociais, acredita que o seu trabalho estabelece um diálogo com os artistas, onde todas as vozes são ouvidas. É através desse discurso polifónico que Fúria propõe outras premissas, outras vozes de desestabilização de verdades absolutas.7

\section{QUEM ESTÁ AUTORIZADO A NOS CONTAR A NOSSA PRÓPRIA HISTÓRIA?}

A autora feminista Djamila Ribeiro apresenta um ponto de vista crítico em relação à hierarquização de saberes como produto da classificação racial da população. Segundo Ribeiro, trata-se de uma equação simples e cruel que possibilita aos «privilegiados sociais o privilégio epistêmico, uma vez que o modelo valorizado e universal da ciência é branco»

7 Entrevista concedida à autora por teleconferência em 8 de agosto de 2020 
(Ribeiro, 2019: 24). Já Grada Kilomba, em Memórias da Plantação, questiona: «a subalterna pode falar?» Recorrendo à Spivak, Kilomba nos diz que a resposta é «não», e acrescenta:

[...] é impossível à subalterna falar ou recuperar a voz, pois mesmo que ela se esforçasse com toda sua força e violência, ainda assim sua voz não seria ouvida ou entendida por quem tem o poder. Nesse sentido, a subalterna não pode realmente falar; ela está sempre confinada à posição de marginalidade e silêncio prescrita pelo pós-colonialismo. (Kilomba, 2019: 47)

Mas em Fúria, «a subalterna» surge como um corpo coletivo que fala e muitas vezes grita a história que tem para contar. O músculo da memória exige trabalho, «ela não se faz espontaneamente. É preciso convocar uma vontade de memória», afirma Regina Abreu (2020). Lia e os artistas da sua companhia convocam esses músculos todos, convocam a vontade da memória e colaboram para a criação coletiva de uma obra coreográfica que revê, de forma crítica, singular e poética, a história do seu país. Eles apresentam uma narrativa através do saber corporal, impregnado no movimento desses bailarinos que sobem e descem diariamente os morros das favelas - muitos, inclusive, desde que nasceram.

De forma contundente, Fúria fala da memória de um país que pouco cultiva, documenta e reflete sobre a sua história, evocando um percurso histórico não-linear tão-pouco cronológico, a partir de uma construção dramatúrgica que evidencia as tensões que afloram de tal ausência. Violência, solidão, medo, opressão, preconceito, racismo, machismo, beleza, sedução, cumplicidade e confiança emergem em cena. Construindo e desmanchando de forma épica um desfile ou uma parada, o trabalho vai criando imagens metafóricas em uma espécie de espiral alucinada. O espetáculo, que faz jus ao título, expõe as inúmeras chagas de uma sociedade em risco. Aqui estão presentes todas as personagens desta história - passado, presente e futuro em potencial - tão esquecida e negligenciada. Nobres colonizadores europeus, homens e mulheres escravizados, imagens mitológicas, políticos, moradores de rua, prostitutas, referências de dinheiro, poder e sexo.

Ouve-se uma música tribal, tambores que embalam e instauram uma espécie de transe nos bailarinos, mas um transe não contemplativo; pelo contrário, uma espécie de transe furioso que desperta uma voz que vem sendo ignorada há séculos e já não pode mais se calar.
O palco, cuja cenografia é deliberadamente sombria e precária, é preenchido por objetos cotidianos (segundo a coreógrafa, todos reciclados de espetáculos anteriores da companhia), coisas que poderiam ser encontradas no lixo. Rodrigues reconhece atitudes ecológicas nas suas criações - de certo modo, até antropofágicas. Não somente adereços e figurinos são reutilizados, mas também incorporadas cenas de espetáculos anteriores neste e em outros trabalhos. Segundo a coreógrafa, suas criações se autodevoram, «no sentido ecológico de reutilizar ideias, quadros, ainda que sejam transformados, porque vêm de outras formas e em outro momento» (Rodrigues, 2019).

Em Fúria, os objetos e figurinos manipulados pelos bailarinos vão sendo ressignificados e transformados em um diálogo minuciosamente construído. Bailarinos avançam, desfilando imagens e referências evocativas de algo que não reconhecemos imediatamente, mas que nos parecem familiares, construindo uma sequência de quadros vivos. Vislumbramos, simultaneamente, nesse desfile, a exuberância festiva das ruas brasileiras e o horror e a desordem dessas mesmas ruas. Lado a lado, pode-se ver a riqueza e a pobreza, a força e a vulnerabilidade, o claro e o escuro, o medo e a coragem de um povo, de uma sociedade, onde coexistem tantos contrastes. Furiosamente a obra consegue nos apresentar, através das influências inscritas nos corpos únicos de cada um dos seus bailarinos, toda a complexidade da paradoxal sociedade brasileira. Durante aproximadamente uma hora, somos testemunhas de uma colaboração coletiva, que constrói uma ideia de grupo, sem apagar a subjetividade e as singularidades de cada artista em cena.

Este tipo de trabalho tem um mérito ainda maior no Brasil, pois rompe com um modelo de produção artística, evidente na dança cênica, que prevalece desde o século xx no país - onde o saber criativo só é validado se houver a chancela europeia. Ou seja, só existe «excelência artística» se o padrão estético estiver associado às poéticas e/ou às técnicas importadas.

Como explica Patricia Hill Collins:

[...] primeiro a ideia de uma subalterna que não pode falar depara-se com a ideologia colonial que os grupos subordinados se identificam incondicionalmente com os poderosos, grupos esses que não têm nenhuma interpretação válida independente da sua própria opressão - logo, não podem falar. Em segundo lugar, a ideia de umas/uns subalternos silenciosos também pode levar à afirmação colonial de que os grupos subordinados 
são menos humanos do que os soberanos, portanto menos capazes de falar em seu próprio nome. (Hill apud Kilomba, 2019: 48)

Ao mesmo tempo, Spivak (2008) adverte os críticos pós-coloniais para o perigo de romantizar os sujeitos resistentes. Nesse sentido, Rodrigues e seus colaboradores parecem estar atentos para não transformar a sua obra em uma espécie de «safari de favelas». Eles não estão expondo suas misérias a um voyeurismo, como o praticado pelo turismo crescente que atravessa as favelas de cidades como Rio de Janeiro, Cidade do Cabo e Johanesburgo. Não se trata de uma ode à pobreza, uma celebração à miséria; mas sim, um alerta, um espelhamento de uma sociedade em estado de falência, cuja omissão de políticas públicas efetivas faz de todos nós, espectadores, confortáveis em nossas cadeiras de plateia, agentes co-responsáveis.

Desse modo, esta obra confronta o paradigma que nega o direito de voz ao subalterno, contrariando as forças de regulação dominantes, Rodrigues o faz de forma lícita e autorizada, e ainda, financiada pelos herdeiros de seus próprios colonizadores ancestrais.

\section{APAGAR PARA SOBREVIVER}

O samba enredo da Mangueira, no carnaval de 2019, afirma que «desde 1500, tem mais invasão que descobrimento». A escola carioca expôs, no seu desfile vencedor, muitas das memórias oprimidas, além de dar protagonismo a líderes invisibilizados da nossa história. A letra do samba diz sem meias palavras:

Ao dizer que o Brasil foi descoberto e não dominado e saqueado; ao dar contorno heroico aos feitos que, na realidade, roubaram o protagonismo do povo brasileiro; ao selecionar heróis «dignos» de serem eternizados em forma de estátuas; ao propagar o mito do povo pacífico, ensinando que as conquistas são fruto da concessão de uma «princesa» e não do resultado de muitas lutas, conta-se uma história na qual as páginas escoIhidas o ninam na infância para que, quando gente grande, você continue em sono profundo. (Miranda, 2019)

Retomando a questão formulada no início deste texto, que trata da dificuldade dos brasileiros em cultivar uma memória crítica da sua história, me pergunto o quanto não foi/é estratégico tal esquecimento. Estratégia de controle, por parte de modelos políticos de manipulação e doutrinamento de uma sociedade que vem sendo explorada há séculos, mas também, por outro lado, uma estratégia de resistência e até mesmo de sobrevivência.

A memória supõe o esquecimento, mais do que isso, como aponta Izquerdo, «o esquecimento é a outra cara da memória [...] é muito mais o que esquecemos do que recordamos» (Izquerdo, 2000: 103). Mas aqui não estamos falando da memória individual, mas sim da memória de uma sociedade, de um país. Trata-se de uma relação da memória coletiva com uma (suposta) identidade nacional.

Nesse sentido, parece oportuno aproveitarmos três conceitos que emergem da análise do discurso, para encontrarmos pistas que possam ampliar e problematizar este estigma de «um país sem memória». Paveau (2013) desenvolveu o conceito de «des-memória», cunhado inicialmente por Robin (2001). Tal conceito pode nos auxiliar na compreensão dessa lógica de esquecimento como forma de autodefesa. Trata-se da escolha de um apagamento da memória mais recente para trazer à luz uma memória mais antiga. O exemplo dado pela autora é o da troca de nomes de ruas ou praças, e até mesmo de cidades - como é o caso de Leningrado, que voltou a se chamar São Petersburgo, em 1991, após a queda do Muro de Berlim. A partir de tal «des-batismo»e «re-batismo», uma nova memória é convocada, através de uma revisão, ou reformulação histórica que pode promover «efeitos transgressivos ou contraintuitivos num contexto em que reine um acordo semântico, histórico e até mesmo ético» (Paveau, 2013: 157). A autora aponta ainda que existem inúmeros processos ao serviço da des-memória, no que tange, particularmente, aos elementos ligados ao sentido e ao referente das palavras.

Outro conceito pertinente para esta discussão é o de «a-memória discursiva» (Paveau, 2013). Conforme mencionado, o esquecimento é necessário para a elaboração da memória, no entanto, quando a formulação desta é impossibilitada pelo trauma, pela opressão e pela dor, o próprio esquecimento pode ser inviável. Não se trata de uma reformulação ou revisão, como no caso da des-memória, ao contrário, como define Paveau:

[M]as sim um apagamento, consciente ou inconsciente, de um passado ou de um legado discursivo, de «formulações-origens» (Courtine) sobre os quais o locutor não quereria ter mais nada a dizer, mas são ditos mesmo 
que pelo viés do inconsciente e da somatização, ou ainda, nas linguagens infinitamente inovadoras do sintoma. (Paveau, 2013: 158)

Assim, esse silêncio habitado por falas não ditas, por um passado não vivido - que porém se manifesta pela dor - evoca, além da a-memória, uma terceira elaboração, ainda proveniente da análise do discurso, denominada «pós-memória». Este conceito, elaborado por Hirsch, está associado a uma memória indireta, não vivida em primeira pessoa, mas herdada de ancestrais. No caso de Fúria, por exemplo, os bailarinos não viveram a escravidão sofrida por seus antepassados mais distantes (no caso dos bailarinos afro-descendentes), ou mesmo a ditadura vivida por seus pais, mas são capazes de reviver essa memória, que lhes foi transmitida através de narrativas, descrições e imagens.

A pós-memória distingue-se da memória por uma distância de geração, e da história por um relato de emoções pessoais. A pós-memória é uma forma muito poderosa e muito particular de memória, precisamente porque sua relação com os objetos e com as fontes não é mediada pelas lembranças, mas por um investimento imaginário e pela criação. Isso não quer dizer que a memória não seja mediada, mas é que ela está mais diretamente religada ao passado. A pós-memória caracteriza a experiência dos que cresceram envolvidos por narrativas, por acontecimentos que precederam seu nascimento, cuja história pessoal foi como que evacuada pelas histórias das gerações precedentes que viveram os acontecimentos e as experiências traumatizantes. (Hirsch apud Paveau, 2013)

Tais conceitos podem nos auxiliar a desfazer o estigma, este rótulo que define o Brasil como um país sem memória tão simplesmente. Pelo contrário, existe uma memória latente e ela vem sendo cada vez mais escancarada, e os artistas têm dado a ver essa transformação. Miranda alerta para a importância de tais manifestações para driblar o autoritarismo e o conservadorismo que estamos enfrentando no atual momento político brasileiro. O compositor afirma:

Acho que vai ficar mais aguda a tentativa de apagamento, de desconstrução da cultura popular, principalmente ligada às origens africanas, às manifestações culturais, religiosas e sociais verdadeiramente populares do Brasil (Miranda, 2019).
Embora Fúria, tal como o samba enredo da Mangueira, faça um retrato impiedoso da dor, de memórias enterradas, de histórias não ditas, a par do momento atual do Brasil, parece evidente que não estão falando somente desta sociedade sul-americana, mas sim de toda uma sociedade ocidental capitalista em crise profunda e em urgente estado de alerta, com crescentes ondas de xenofobia e de um alarmante fortalecimento da extrema-direita. Ainda que tal retrato não seja fácil de se ver, não está a passar despercebido, e talvez justamente por isso, uma certa produção artística brasileira venha tendo o apoio financeiro, a abertura e uma visibilidade maiores na Europa do que em seu próprio país. No entanto, se existe uma Europa que olha para as periferias do mundo, apoiando e financiando projetos como este, há também uma Europa que blinda e constrói muros. Uma pequena ilustração de tal bloqueio foi abertamente testemunhada em uma apresentação de Fúria em Viena, Áustria, quando, quase no final da apresentação, um homem branco se levantou, e com a sua própria fúria, gritou em alemão: «Vistam-se e voltem para o seu país» (Repetto, 2019).

\section{ENTRETANTO, EXISTEM ALTERNATIVAS?}

Entretanto, existem alternativas? Menos furiosas talvez? Vladimir Safatle aposta que sim. O pensador brasileiro aponta:

[...] alternativas existem, mas se elas forem implementadas serão outros afetos que circularão, fortalecendo aqueles que recusam tal lógica fascista, permitindo enfim que eles imaginem outro corpo social e político. Tais alternativas passam pela consolidação da solidariedade genérica que nos faz sentir em um sistema de mútua dependência e apoio, no qual minha vida depende da vida daqueles que sequer fazem parte do «meu grupo», que estão no «meu lugar», que tem as «minhas propriedades» (Safatle, 2020).

Desse modo, Fúria não é somente um fenômeno revelador de desgovernos atuais, mas também uma forte manifestação da nossa desconexão intrínseca enquanto sociedade. A problematização histórica nesta obra é então dada a ver como fissura que escancara, ao mesmo tempo, a degeneração da política que pode ser observada no Brasil, em particular, mas também em outros países nesse momento. A obra nos revela ainda 
como os processos de apagamento através de uma memória construída são capazes de perpetuar as estruturas de poder, impostas culturalmente. É nesse ponto que as artes, em geral, e, nesse caso específico, a dança contemporânea, adquirem o seu potencial transformador, uma vez que é através do fazer artístico que memórias latentes e soterradas podem ser resgatadas e reinventadas, criando condições reais de mudança.

Entretanto, é necessário não somente resistir, mas principalmente insistir, para que alternativas aconteçam. Os artistas vão continuar a desnudar a história e a escancarar memórias, de formas doces ou furiosas, em suas próprias paragens, mas também em muitos outros portos. $\mathrm{E}$ se os tempos são de dor, medo e violência, também são de emancipação e de coragem. Seja nas ruas, nos livros ou nos palcos, novos corpos e vozes vêm cavando buracos, ou preenchendo-os com outros pontos de vista da história do Brasil, das ex-colônias e dos povos oprimidos.

\section{REFERÊNCIAS BIBLIOGRÁFICAS}

ABREU, Regina (2020), «Incêndio no Museu Nacional Provoca Reflexão. Brasil um País Sem Memória» in https:// oglobo.globo.com/cultura/incendio-no-museu-nacional-provoca-reflexao-brasil-um-pais-sem-memoria-23050497, acessado em 20/02/2020.

ECKERT, Cornélia, e ROCHA, Ana Luiza (2000), A retórica do mito do progresso, «Brasil um país sem memória» in https://seer.ufrgs.br/iluminuras/article/view/9105, acessado em 11/09/2019.

FERnANDES, Sílvia (2018), «O Teatro Expandido em Contexto Brasileiro» in http://www.revistas.usp.br/ salapreta/article/view/146758/141508, acessado em 20 de agosto de 2020.

IZQUERDO, Ivan (2000), Memória, in http://www.scielo.br/pdf/ea/v3n6/v3n6ao6.pdf, acessado em 22/02/2020.

KATZ, Helena (2019), «Acordar a fúria», texto do programa do DDD, Teatro Nacional São João, Porto.

кILOMBA, Grada (2019), Memórias da Plantação, trad. Nuno Quintas, Lisboa, Orfeu Negro.

MIRANDA, Tomaz (2019), «Samba da Mangueira traz Marielle e Dandara e a história que a História não conta», https://www.redebrasilatual.com.br/cultura/2019/03/samba-da-mangueira-traz-marielle-e-dandara-e-a-historia-que-a-historia-nao-conta/, acessado em 01/05/2020.

PAVEAU, Marie-Anne (2013), «Memória, des-memória, a-memória: quando o discurso volta-se para seu passado», trad. Jocilene Santana Prado e Eduardo Lopes Piris, EID\&A - Revista Eletrônica de Estudos Integrados em Discurso e Argumentação, Ilhéus, n. ${ }^{\circ}$ 5, pp. 137-161.

RIBEIRO, Djamila (2019), Lugar de Fala, São Paulo, Pólen.

RODRIGUES, Lia (2020), RFI Convida Lia Rodrigues, in https://www.youtube.com/watch?v=12A41aK9z9s\&$\mathrm{t}=337 \mathrm{~s}$, acessado em 20/03/2020.

SAFATLE, Wladimir (2020), «Bem vindo ao estado Suicidário», https://jornalggn.com.br/blog/doney/bem-vindo-ao-estado-suicidario-por-vladimir-safatle-n-1-edicoes/, acessado em 20/03/2020.

SPIVAK, Gayatri (2008), The Trajectory of The Subaltern in my Work, in https://www.youtube.com/watch?v=2ZHH4ALRFHw, acessado em 20/04/2020.

\section{ENTREVISTAS CEDIDAS À AUTORA POR TELECONFERÊNCIA}

MAREU Machado, 10 de setembro de 2019

CAROL Reppetto, 3 de dezembro de 2019.

LIA Rodrigues, 8 de agosto de 2020.

\section{GISELA DÓRIA}

Coreógrafa, formada pelo College da Royal Academy of Dance. É pós-doutorada pela Escola de Comunicações e Artes da Universidade de São Paulo e pela Universidade de Lisboa. É doutora em Artes da Cena pela Unicamp e mestre em Artes Cénicas pela Universidade de São Paulo. É autora de A Poética de Sem Lugar: Por Uma Teatralidade na Dança (Editora Perspectiva, 2013). 